\title{
Review Article \\ Dysregulation of Protein Phosphorylation/Dephosphorylation in Alzheimer's Disease: A Therapeutic Target
}

\author{
Cheng-Xin Gong, Fei Liu, Inge Grundke-Iqbal, and Khalid Iqbal \\ Department of Neurochemistry, New York State Institute for Basic Research in Developmental Disabilities, 1050 Forest Hill Road, \\ Staten Island, NY 10314-6399, USA
}

Received 8 November 2005; Revised 12 December 2005; Accepted 3 January 2006

Studies during the last two decades have provided new insights into the molecular mechanism of Alzheimer's disease (AD). One of the milestone findings in $\mathrm{AD}$ research was the demonstration that neurofibrillary degeneration characterized by tau pathology is central to the pathogenesis of $\mathrm{AD}$ and other tauopathies and that abnormal hyperphosphorylation of tau is pivotal to neurofibrillary degeneration. This article reviews the recent research advances in tau pathology and the underlying dysregulation of the protein phosphorylation/dephosphorylation system. An updated model of the mechanism of neurofibrillary degeneration is also presented, and a promising therapeutic target to treat $\mathrm{AD}$ by correcting dysregulation of protein phosphorylation/dephosphorylation is discussed.

Copyright (C) 2006 Cheng-Xin Gong et al. This is an open access article distributed under the Creative Commons Attribution License, which permits unrestricted use, distribution, and reproduction in any medium, provided the original work is properly cited.

\section{INTRODUCTION}

Although Alzheimer's disease (AD) and its main brain histopathology, that is, senile plaques and neurofibrillary tangles (NFTs), were described a century ago, significant research advances in the disease began only a few decades ago. The discoveries of the major protein components of senile plaques as amyloid $\beta$-peptide $[1,2]$ and of NFTs as abnormally hyperphosphorylated tau $[3,4]$ in the 1980s initiated a new era of AD research. Since then, much research has focused on the molecular mechanisms of initiation and formation of the senile plaques and NFTs and their roles in the pathogenesis of AD. Evidence accumulated in the last two decades indicates that malprocessing of both tau and $\beta$-amyloid precursor protein, which produces $\beta$-peptide, is pivotal, if not central, to the molecular mechanism of AD. The severity of dementia symptoms in AD strongly correlates to the number of NFTs, but not of senile plaques, in AD brains [5-9], suggesting that tau pathology might be associated with the disease mechanism more directly. Abnormal hyperphosphorylation of tau and its deposits in the brain is also seen in several other neurodegenerative diseases that are collectively named tauopathies (for review, see $[10,11]$ ). The discovery of tau mutations that cause hereditary frontotemporal dementia and Parkinsonism linked to chromosome 17 (FTDP17) $[12-14]$ further indicates that tau abnormality alone is sufficient to produce dementia. Therefore, for developing rational therapeutic treatment of $\mathrm{AD}$, it is essential to understand the molecular mechanism by which tau abnormalities lead to neurofibrillary degeneration.

Because tau aggregated in the brain of $\mathrm{AD}$ and all other tauopathies is always abnormally hyperphosphorylated, numerous studies have focused on the roles of the abnormal hyperphosphorylation and the mechanism leading to tau hyperphosphorylation. Recent studies demonstrate that it is the abnormal hyperphosphorylation that makes tau lose its normal function to stimulate microtubule assembly, gain toxic activity, and aggregate into NFTs [15-23]. In addition to tau, several other brain proteins such as neurofilaments, microtubule-associated protein (MAP) $1 \mathrm{~B}, \beta$ tubulin, and $\beta$-catenin are also found to be hyperphosphorylated [24-27], suggesting that the protein phosphorylation/dephosphorylation system might be dysregulated in $\mathrm{AD}$ brain. This article attempts to review the recent advances in this respect. Because abnormally hyperphosphorylated tau is pivotal to $\mathrm{AD}$ and has been extensively studied, this review focuses on tau hyperphosphorylation. Prevention and reversal of abnormal hyperphosphorylation of tau as a potential promising therapeutic strategy is also discussed.

\section{TAU PROTEIN}

Tau was first discovered by Weingarten et al [28] as a microtubule-associated protein that stimulates microtubule 
assembly. There was not much research interest in tau protein until a decade later, when it was found to make up the paired helical filaments (PHFs) that form NFTs in AD brain $[3,4,29]$. Human tau gene was found on the long arm of chromosome 17 (position 17q21) and was found to contain 16 exons [30]. This single tau gene encodes six tau isoforms in adult human brain as a result of alternative splicing of its mRNA [31]. The six isoforms of tau differ from each other by the presence or absence of one or two inserts (29 or 58 amino acids) in the $N$-terminal part and by the presence of either three or four repeats in the $C$-terminal half. The $N$-terminal inserts are highly acidic. The repeats in the $C$-terminal half of tau are the domains that bind to microtubules [32-34]. The region upstream of the microtubule-binding domains contains many proline residues and, hence, is called the prolinerich region.

The best-known biological functions of tau are to stimulate microtubule assembly and to stabilize microtubule structure. Tau binds to microtubules via its microtubule-binding domains located at the $C$-terminal half of the molecule [3234]. The $N$-terminal part projects from the microtubule surface, where it may interact with other cytoskeletal elements and the plasma membrane $[35,36]$. Each of the six tau isoforms possibly has its particular physiological roles and differential biological activities, because they are differentially expressed during development and have different activities to stimulate microtubule assembly $[37,38]$. Only the shortest isoform of tau is expressed in fetal brain, whereas all six isoforms are seen in adult brain $[39,40]$. In addition to stimulating microtubule assembly, several studies have suggested that tau may have other physiological functions. It appears to interfere with binding of kinesin and kinesin-like motors to microtubules, leading to a preferential inhibition of plus-end-directed axonal transport [41]. Overexpression of tau inhibits kinesin-dependent trafficking of vesicles, mitochondria, and endoplasmic reticulum [42]. This may explain the symptoms of amyotrophic lateral sclerosis with neurofilament accumulation in motor neurons of several transgenic models of tau overexpression [43-46]. Tau has been found to interact with mitochondria [47], plasma membrane [36], and nucleic acids $[48,49]$, suggesting that it may act as mediator between microtubules and these organelles. Tau also appears to interact with src-family nonreceptor tyrosine kinases such as fyn $[50,51]$ and phospholipase $C-\gamma[52,53]$ via its proline-rich region. These data suggest that tau may also play a role in the signal transduction pathways involving srcfamily tyrosine kinases and phospholipase $C-\gamma$. However, the physiological significance of these interactions remains to be elucidated.

As early as 1977, tau was found to be a phosphoprotein [54]. In 1984, it was demonstrated that phosphorylation of tau negatively regulates its activity in promoting microtubule assembly [55]. Because tau is abnormally hyperphosphorylated in $\mathrm{AD}$ and other tauopathies, tau phosphorylation has been studied extensively. Normal brain tau contains 2 or 3 moles of phosphates per mole of tau [56-58]. Studies on human brain biopsy tissue indicated that several serine and threonine residues of tau are normally phosphorylated at substoichiometrical levels $[59,60]$. A normal level of phosphorylation appears to be required for tau's optimal function, whereas the hyperphosphorylated tau loses its biological activity [15, 16, 61-69].

\section{ABNORMAL HYPERPHOSPHORYLATION OF TAU IN AD BRAIN}

The discovery that tau aggregated in AD brain is abnormally hyperphosphorylated has stimulated many studies on the extent and sites of tau hyperphosphorylation and their role in the pathogenesis of AD. The phosphorylation level of tau isolated from autopsied $\mathrm{AD}$ brains is 3- to 4-fold higher than that from normal human brains [56-58]. In addition, the hyperphosphorylated tau is accumulated in both brains $[70,71]$ and cerebral spinal fluid [72-80] of individuals with AD. All six isoforms of tau are aggregated into PHFs in the abnormally hyperphosphorylated forms in $\operatorname{AD}$ brains $[3,4$, $31,81]$. To date, at least 37 serine and threonine residues have been found to be phosphorylated in PHF-tau (for review, see [82]). These residues include Thr39, Ser46, Thr69, Thr123, Ser137, Thr153, Thr175, Thr181, Ser198, Ser199, Ser202, Thr205, Ser208, Ser210, Thr212, Ser214, Thr217, Thr231, Ser235, Ser237, Ser238, Ser241, Ser262, Ser285, Ser305, Ser324, Ser352, Ser356, Ser396, Ser400, Thr403, Ser404, Ser409, Ser412, Ser413, Ser416, and Ser422. Many of these residues are also phosphorylated in normal human brains without NFTs at smaller extents, but they are rapidly dephosphorylated during postmortem delay and tissue processing $[59,60]$. However, the phosphate groups at these sites are not readily dephosphorylated during the postmortem period and tissue processing of $\mathrm{AD}$ brain, probably because of the deficient protein phosphatase activities [83-89]. Some of the phosphorylation sites seen in PHFtau are not phosphorylated at all in normal brains. These sites include Thr212/Ser214, Thr231/Ser235 [90], and Ser422 $[91,92]$.

Because all of the previously identified phosphorylation sites of normal tau and PHF-tau are at either serine or threonine residues, it was thought that tau was phosphorylated only at serine and threonine residues. However, recent studies suggest that tau in developing brain and in $\mathrm{AD}$ brain is also phosphorylated at tyrosine residues. The src-family nonreceptor tyrosine kinase fyn can bind to and phosphorylate tau in vitro and in transfected cells $[50,51,93]$. The phosphorylation site of tau was mapped as Tyr18. Tyrosine phosphorylated tau at this position is also seen immunohistochemically in the brain of transgenic mice that express mutated human taup301L [51]. Williamson et al [94] demonstrated that in primary human and rat brain cortical cultures tau is phosphorylated at Tyr 29 upon treatment with $A \beta$. The tyrosine phosphorylation of tau appears rapid and transient. Interestingly, antibodies specific to tyrosine phosphorylated tau labeled purified PHF-tau, but not normal tau, suggesting that PHF-tau is phosphorylated at the tyrosine residues $[93,94]$. In addition, Tyr394 was also found to be phosphorylated in PHF-tau and in tau from fetal brains, and the phosphorylation at this site is catalyzed by another nonreceptor 
tyrosine kinase $c$-Abl [95]. It is not clear if the phosphorylation at any of the above tyrosine residues is stoichiometrically significant. Therefore, whether the tyrosine phosphorylation of tau has any pathophysiological relevance remains to be elucidated.

Numerous studies have demonstrated the important role of abnormal hyperphosphorylation of tau in its aggregation into NFTs and in Alzheimer's neurofibrillary degeneration. In cultured cells, hyperphosphorylation of tau after treatment with phosphatase inhibitors impairs its activity to bind to microtubules and induces filamentous aggregation of tau [21]. Pseudohyperphosphorylated tau that simulates abnormally hyperphosphorylated tau by mutation of serine or threonine residues into glutamate at selected $\mathrm{AD}$ related sites exerts a cytotoxic effect, whereas wild-type tau is neutral [22]. In contrast, neurons from tau-knockout mice are resistant to $\mathrm{A} \beta$-induced neurotoxicity [96]. Overexpression of human tau in combination with phosphorylation by Drosophila GSK-3 $\beta$ homologue Shaggy, but not tau overexpression alone, exacerbates tau-induced neurodegeneration and results in the formation of NFT-like filamentous tau aggregates [23]. This study shows a causal relationship between tau hyperphosphorylation and neurofibrillary degeneration in vivo. A study in Disabled-1 (an adapter protein) knockout mice further demonstrates that tau hyperphosphorylation causes early death of the animals [97]. Most importantly, tau in inclusions of all tauopathies in human and animal models is always hyperphosphorylated (for reviews, see $[11,98]$ ). Abnormal hyperphosphorylation of tau appears to precede its aggregation into NFTs in AD brain [57, 99-101]. Taken together, these studies suggest that the abnormal hyperphosphorylation of tau is crucial to neurofibrillary degeneration in $\mathrm{AD}$ and other tauopathies.

The largest isoform of human brain tau (441 amino acids) contains 80 serine and threonine residues and five tyrosine residues [31]. Phosphorylation at nearly half of these residues has been reported in PHF-tau (see [82] for review). Many studies have demonstrated that phosphorylation of tau at different sites has different impacts on its biological function and on its pathogenic role. For instance, a quantitative in vitro study demonstrated that phosphorylation of tau at Ser262, Thr231, and Ser235 inhibits its binding to microtubules by $\sim 35 \%, \sim 25 \%$, and $10 \%$, respectively [102]. In cultured cells, phosphorylation of tau at Ser214 and Ser262 decreases its binding to microtubules and appears to inhibit its assembly to filaments [103]. In vitro kinetic studies of the binding between hyperphosphorylated tau and normal tau suggest that phosphorylation of tau at Ser199/Ser202/Thr205, Thr212, Thr231/Ser235, Ser262/Ser356, and Ser422 are among the critical phosphorylation sites that convert tau to a toxic molecule to sequester normal MAPs from microtubules [19]. Further phosphorylation at Thr231, Ser396, and Ser422 promotes self-assembly of tau into filaments. Similarly, tau mutated at Ser396 and Ser404 (changing Ser into Glu) to mimic phosphoserine is more fibrillogenic than wild-type tau [104], and a tau construct in which Ser422 is mutated to Glu shows a significantly increased propensity to aggregate [105]. Consistent with these observations is that mutation of Ser422 to Ala prevents $A \beta$-induced tau aggregation [106]. These results suggest that phosphorylation of Ser422 may play a key role in tau filament formation in vivo.

An important question is, by what mechanism is the tau abnormality involved in the pathological cascades that lead to neurodegeneration in $\mathrm{AD}$ and other tauopathies. Does a hyperphosphorylation-induced defect in its activity to stimulate microtubule-assembly contribute to cell dysfunction? Is it the formation of insoluble tau aggregates that is pathogenic? Although tau loses its activity to stimulate microtubules, lack of overt phenotype of tau knockout transgenic mice [107] suggests that it is very unlikely that tau abnormality contributes to neurodegeneration via loss of normal function due to its hyperphosphorylation. By a series of studies, we have found that both the abnormally hyperphosphorylated tau isolated from $\mathrm{AD}$ brain and in vitro hyperphosphorylation tau gain a toxic activity to sequester normal tau and other MAPs, such as MAP1 and MAP2, and cause microtubule disassembly $[16,18,66,108]$. Upon dephosphorylation, they lose this toxic activity. Polymerization of the hyperphosphorylated tau into PHFs also abolishes this toxic activity (Alonso $\mathrm{A}$ et al, unpublished observation). Hence, we speculate that the abnormal hyperphosphorylation of tau causes neurodegeneration by gain of toxic activity rather than by loss of normal activity that can be compensated for by other MAPs and that formation of PHFs/NFTs from the hyperphosphorylated tau in neurons is a defense mechanism by which neurons aim to reduce the toxic activity of the abnormally hyperphosphorylated tau. This speculation is supported by recent in vivo studies. Conditional overexpression of GSK-3 $\beta$ in the transgenic mouse brains induces tau hyperphosphorylation and neurodegeneration, but no tau aggregation [109]. In contrast, there are NFTs but no memory loss in several lines of tau transgenic mice (for review, see [110]). This phenomenon is probably common to other diseases characterized by abnormal protein aggregates such as Huntington disease and cardiomyopathy, in which the abnormal, nonfibrillar protein oligomers, rather than the aggregates themselves, appear to be pathogenic $[111,112]$.

\section{IMBALANCE OF PHOSPHORYLATION/ DEPHOSPHORYLATION IN AD BRAIN}

To understand the mechanism leading to abnormal hyperphosphorylation of tau in $\mathrm{AD}$, protein kinases and phosphatases that regulate tau phosphorylation level must be identified first. In the last two decades, numerous studies aimed to the identification of tau kinases and phosphatases have been carried out. It was found that in vitro, dozens of phosphoseryl/phosphothroenyl protein kinases and most of the major protein phosphatases could act on tau protein at various phosphorylation sites (for reviews in detail, see $[82,113,114])$. Tau appears to be a universal substrate for protein kinases and phosphatases in vitro. This may not be surprising, because nearly $20 \%$ of the amino acid residues of tau molecule are serines and threonines, and nearly $50 \%$ of these residues are phosphorylated to certain degrees in $\mathrm{AD}$ 
brain (see [82] for review). However, it is unlikely that all these enzymes that act on tau in vitro catalyze tau phosphorylation/dephosphorylation in vivo. Immunohistochemical studies also have shown a colocalization of more than a dozen protein kinases and several protein phosphatases with NFTs of AD brain. As we now know that NFTs are very "sticky" structures that can be stained immunohistochemically by antibodies to numerous antigens, immunohistochemical colocalization with NFTs can only support other data that indicate a role of the specific protein or enzyme in the formation of NFTs, but itself cannot indicate such a role.

Further studies in cultured cells, in situ, and especially in vivo suggest that a few protein kinases and phosphatases may be involved in regulation of tau phosphorylation in the brain. The kinases that most likely play a role in phosphorylation of tau in the brain include glycogen synthase kanase-3 $\beta$ (GSK$3 \beta)$, cyclin-dependent kinase 5 ( $c d k 5)$, cAMP-dependent protein kinase (PKA), stress-activated protein kinases, and calcium/calmodulin-dependent kinase II (CaMK-II). Johnson and Stoothoff [115] have critically discussed this issue. The sites of tau phosphorylation by these kinases, except stress-activity protein kinases, have been summarized in our recent review [82]. Among protein phosphatases, PP2A has been shown to be the major tau phosphatase in the brain $[69,116-120]$. In a recent study, we compared the catalytic kinetics of tau dephosphorylation by various major brain protein phosphatases and determined the relative contributions of these phosphatases to the regulation of tau phosphorylation quantitatively. We found that PP2A accounts for $\sim 70 \%$ of the total tau phosphatase activity, whereas PP1, PP2B, and PP5 each accounts for only $\sim 10 \%$ of the total tau phosphatase activity [88]. Because PP2B activity is upregulated rather than downregulated in $\mathrm{AD}$ brain, it is unlikely that it regulates tau phosphorylation in vivo [121].

Accumulated evidence indicates that tau phosphorylation is regulated by several protein kinases and that more than one kinase might be involved in abnormal hyperphosphorylation of tau in AD brain. Interestingly, GSK-3 $\beta$ phosphorylates tau at both prime sites (ie, tau needs to be primed by phosphorylation with other kinases at other sites) and unprimed sites [122-126]. In a cotransfection study, Cho and Johnson [125] found that a GSK-3 $\beta$ mutant (GSK-3 $\beta$-R96A) that only phosphorylates unprimed sites has no negative impact on tau's ability to bind to microtubules, in contrast to wild-type GSK-3 $\beta$, which significantly impairs tau's ability to bind to microtubules. Further studies demonstrate that primed phosphorylation of tau at Thr231 by GSK-3 $\beta$ plays a critical role in decreasing tau's ability to both bind to and stabilize microtubules [126]. In rat brains, activation of PKA not only induces primed phosphorylation of tau by GSK-3 $\beta$, but also impairs the spatial memory of rats [124, 127]. GSK$3 \beta$ appears to be regulated by both phosphoinositol-3 kinase and protein kinase $C$ pathways [128-131].

An obvious approach to understanding how tau becomes abnormally hyperphosphorylated in AD is to study whether tau kinase(s) or tau phosphatase(s) are dysregulated in $\mathrm{AD}$ brain. Several studies have focused on whether the activities and expression of these enzymes are altered in $\mathrm{AD}$ brain.
Among protein kinases, cdk5 was reported to be upregulated in AD brain by one laboratory [132], but this result was challenged by others [133-136]. On the other hand, both the activity and the expression of PP2A as well as the activities of PP1 and PP5 are decreased in the selected areas of AD brain [83-89]. Consistent with this finding, several other neuronal proteins such as neurofilaments, MAP1B, $\beta$-tubulin, and $\beta$ catenin are also hyperphosphorylated in AD brain [24-27]. Hence, it appears that downregulation of the phosphatases, especially of PP2A, might underlie the abnormal hyperphosphorylation of tau and other proteins in $\mathrm{AD}$ brain. Studies of metabolically active rat brain slices and transgenic mice suggest that the downregulation of PP2A may produce hyperphosphorylation of tau, not only by the deficient dephosphorylation of tau, but also through the activation of several PP2A-regulated protein kinases, including PKA [137], CaMK-II [138], MAP kinases, and stress-activated protein kinases [139-141]. Nevertheless, inhibition of PP2A activity in animal brain could only induce hyperphosphorylation of tau at some of the hyperphosphorylation sites seen in PHFtau, but does not result in NFTs. Attempts to produce massive tangles of PHFs in animal models merely via alteration of tau phosphatase and/or kinase activities have not yet been successful. These observations suggest that the downregulation of tau phosphatases in AD brain may be only partially responsible for the abnormal hyperphosphorylation of tau.

The causes leading to decreased PP2A activity in AD brain are not well understood. Downregulation of PP2A expression [85] and upregulation of PP2A endogenous inhibitor proteins $\mathrm{I}_{1}^{\mathrm{PP} 2 \mathrm{~A}}$ and $\mathrm{I}_{2}^{\mathrm{PP} 2 \mathrm{~A}}[142]$ in $\mathrm{AD}$ brain may both contribute to the downregulation of PP2A activity. Because the activities of PP1 [83, 88] and PP5 [88, 89], which contribute to regulation of tau phosphorylation to a much smaller extent than PP2A [88], are also decreased in AD brain, there might be a common factor that downregulates the activities of the major brain protein phosphatases in $\mathrm{AD}$ brain.

In addition to tau kinases and phosphatases, alterations of tau itself, the substrate of these enzymes, may also play an important role in its abnormal hyperphosphorylation and conversion into PHFs. Tau is also modified post-translationally by $\beta-N$-acetylglucosamine (GlcNAc) via a glycosidic bond at the hydroxyl groups of serine and/or threonine residues, and this modification is called $O$ GlcNAcylation [143-145]. Because O-GlcNAc could modify the same serine or threonine residues of tau as phosphate does and a reciprocal relationship between $O$-GlcNAcylation and phosphorylation has been seen in many proteins (for review, see [146]), O-GlcNAcylation could affect phosphorylation of tau. Recent studies in various systems found that tau phosphorylation is indeed regulated by $O$-GlcNAcylation inversely [144, 145, 147]. Most interestingly, fasting of mice induces downregulation of tau O-GlcNAcylation, which relies on glucose metabolism to supply UDP-GlcNAc as a donor for protein O-GlcNAcylation, and in turn leads to hyperphosphorylation of tau [145]. These findings led to the novel hypothesis that impaired glucose uptake/metabolism in AD brain, which was well established decades ago, contributes 


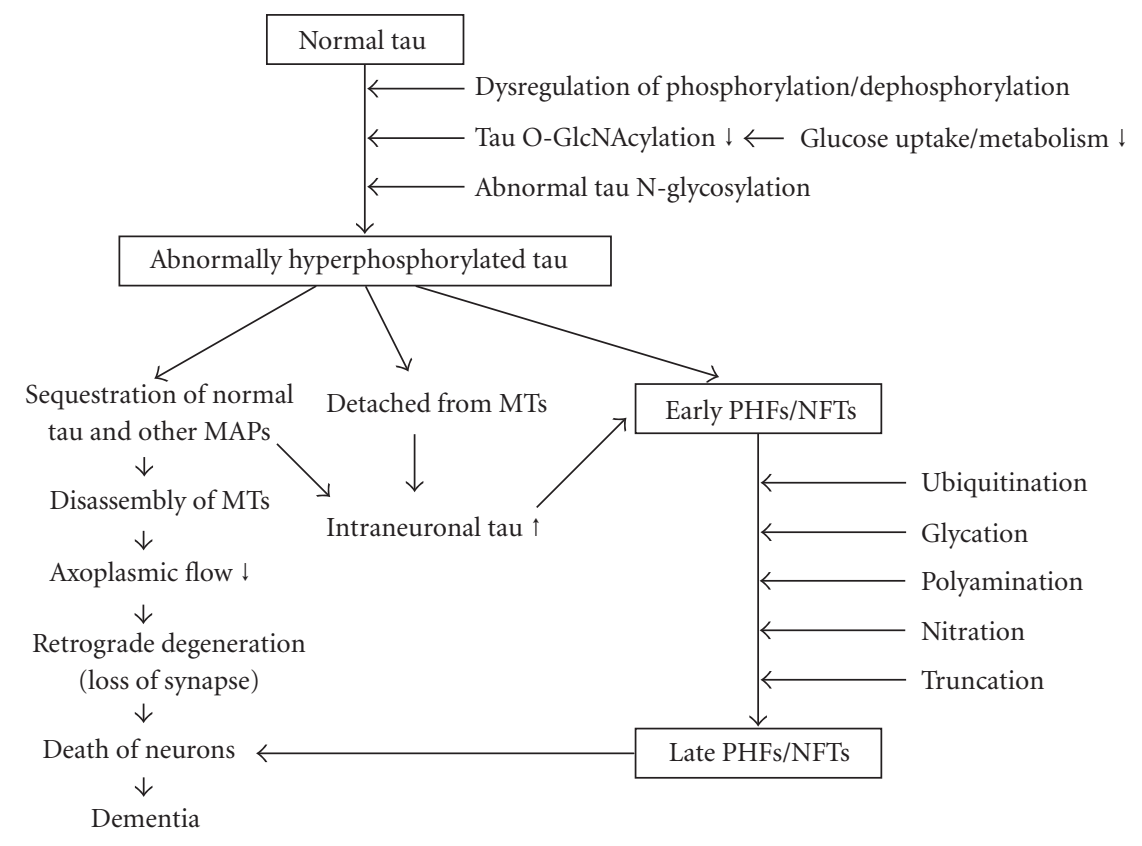

Figure 1: Proposed mechanism of neurofibrillary degeneration. MAPs, microtubule-associated proteins; MTs, microtubules; PHFs, paired helical filaments; NFTs, neurofibrillary tangles.

to the disease pathogenesis via downregulation of tau $O$ GlcNAcylation and, consequently, upregulation of tau phosphorylation that leads to neurofibrillary degeneration [148].

Classical $N$-linked glycosylation is a modification of protein at asparagine residues by oligosaccharides, which normally modifies only membrane proteins and secreted proteins. Tau in AD brain, but not in normal human brain, was found to be modified by $N$-glycosylation $[68,149,150]$, and this aberrant tau modification appears to precede and facilitate abnormal hyperphosphorylation of tau [150-152]. This modification has been reviewed in detail in a recent article [82].

\section{MECHANISM OF NEUROFIBRILLARY DEGENERATION}

There is no doubt that the abnormality of tau plays a central role in neurofibrillary degeneration in $\mathrm{AD}$ and other tauopathies. A critical review of the literature accumulated in the last two decades sheds light onto the probable mechanism of neurofibrillary degeneration of AD (Figure 1).

Tau is the major microtubule-associated protein of mature neurons where it stimulates microtubule assembly and stabilizes microtubule structure. Tau is normally modified by both phosphorylation and $O$-GlcNAcylation. The phosphorylation level of tau is regulated by tau kinases and tau phosphatases, as well as by the alteration of tau itself. In $\mathrm{AD}$ and probably also in other tauopathies, metabolic and genetic abnormalities lead to dysregulation of signal transduction pathways, which in turn causes an imbalance of the phosphorylation/dephosphorylation system, that is, downregulation of $\mathrm{PP} 2 \mathrm{~A}$ in the brain. This imbalance results in increased phosphorylation (ie, hyperphosphorylation) of tau. The impaired brain glucose uptake/metabolism that precedes $\mathrm{AD}$ also facilitates hyperphosphorylation of tau via downregulation of tau O-GlcNAcylation [148]. Aberrant $N$ glycosylation of tau in AD brain also makes tau a more favorable substrate for major tau kinases and less favorable for tau phosphatases [151, 152], thereby facilitating tau hyperphosphorylation.

The abnormally hyperphosphorylated tau resulting from any of the above causes not only loses its biological activity to stimulate microtubule assembly, but also becomes a toxic molecule, sequesters normal tau, MAP1, and MAP2, and causes disassembly of microtubules. The breakdown of the microtubule network in the affected neurons compromises axonal transport and leads to retrograde degeneration, which in turn results in neuronal death and dementia. On the other hand, the abnormally hyperphosphorylated tau detached from microtubules is not only easier to polymerize into PHFs as a result of hyperphosphorylation, but it also causes increased intraneuronal soluble tau concentration due to sequestration of normal tau from microtubules, which further facilitates tau aggregation into PHFs. The polymerized abnormal tau is further modified by ubiquitination, glycation, polyamination, nitration, and truncation (for review, see [82]), and forms mature PHFs/NFTs. Unlike the unpolymerized hyperphosphorylated tau that is toxic, PHFs/NFTs appears to be inert (Alonso A et al unpublished observation), but these lesions grow in size with disease progression 
and eventually might physically choke the affected neuron to death.

\section{THERAPEUTIC TARGET TO TREAT AD BY CORRECTING DYSREGULATION OF PROTEIN PHOSPHORYLATION/ DEPHOSPHORYLATION}

Because neurofibrillary degeneration plays a central role in the pathogenesis of $\mathrm{AD}$, one of the most attractive therapeutic targets of $\mathrm{AD}$ is to inhibit neurofibrillary degeneration. As outlined in Figure 1, the most promising approaches to achieve this goal are to inhibit the abnormal hyperphosphorylation of tau and to inhibit its sequestration of normal MAPs. The former approach is more effective since it should both rescue the disruption of microtubule and axoplasmic flow and prevent further deposition of NFTs. Several academic groups and pharmaceutical companies have been investigating this approach by restoring PP2A activity or inhibiting tau kinase activity in the brain. Memantine, a low-to-moderate-affinity antagonist of NMDA receptor, which improves mental function and the quality of daily life of individuals with moderate to severe AD [153, 154], reverses the okadaic-acid-induced inhibition of PP2A activity and prevents tau hyperphosphorylation in hippocampal slice cultures from adult rats [155]. The restoration of PP2A activity to normal level by memantine also leads to restoration of the expression of MAP2 in the neuropil and a reversal of hyperphosphorylation and accumulation of neurofilaments. Wang's group has demonstrated that treatment of brain slices and rats with melatonin can restore PP2A activity that is inhibited by okadaic acid or calyculin A and reverse hyperphosphorylation of tau and neurofilament proteins as well as cytotoxicities [156-158]. Melatonin also prevents tau hyperphosphorylation and aggregation induced by overactivation of GSK-3 or PKA [131, 159]. These are examples showing that inhibition of dysregulation of protein phosphorylation/dephosphorylation is a promising target to treat $\mathrm{AD}$. Further investigation of new compounds that can inhibit abnormal hyperphosphorylation of tau will likely provide new treatments for $\mathrm{AD}$.

\section{ACKNOWLEDGMENTS}

We are grateful to J Biegelson and S Warren for secretarial assistance and to M Marlow for editorial suggestions. This work was supported in part by the New York State Office of Mental Retardation and Developmental Disabilities and grants from National Institutes of Health (AG16760 to CX Gong, AG19158 to K Iqbal), the Alzheimer's Association, Chicago, Ill (NIRG-03-4721 to F Liu, IIRG-05-13095 to C-X Gong), and the Li Foundation, New York (to C-X Gong).

\section{REFERENCES}

[1] Glenner GG, Wong CW. Alzheimer's disease: initial report of the purification and characterization of a novel cerebrovascular amyloid protein. Biochemical and Biophysical Research Communications. 1984;120(3):885-890.
[2] Masters CL, Simms G, Weinman NA, et al. Amyloid plaque core protein in Alzheimer disease and Down syndrome. Proceedings of the National Academy of Sciences of the United States of America. 1985;82(12):4245-4249.

[3] Grundke-Iqbal I, Iqbal K, Quinlan M, et al. Microtubuleassociated protein tau. A component of Alzheimer paired helical filaments. The Journal of Biological Chemistry. 1986;261(13):6084-6089.

[4] Grundke-Iqbal I, Iqbal K, Tung YC, et al. Abnormal phosphorylation of the microtubule-associated protein tau (tau) in Alzheimer cytoskeletal pathology. Proceedings of the $\mathrm{Na}$ tional Academy of Sciences of the United States of America. 1986;83(13):4913-4917.

[5] Tomlinson BE, Blessed G, Roth M. Observations on the brains of demented old people. Journal of the Neurological Sciences. 1970;11(3):205-242.

[6] Alafuzoff I, Iqbal K, Friden H, Adolfsson R, Winblad B. Histopathological criteria for progressive dementia disorders: clinical-pathological correlation and classification by multivariate data analysis. Acta Neuropathologica (Berl). 1987;74(3):209-225.

[7] Dickson DW, Farlo J, Davies P, et al. Alzheimer's disease. A double-labeling immunohistochemical study of senile plaques. The American Journal of Pathology. 1988;132(1):86101.

[8] Arriagada PV, Growdon JH, Hedley-Whyte ET, et al. Neurofibrillary tangles but not senile plaques parallel duration and severity of Alzheimer's disease. Neurology. 1992;42(3 pt 1):631-639.

[9] Riley KP, Snowdon DA, Markesbery WR. Alzheimer's neurofibrillary pathology and the spectrum of cognitive function: findings from the Nun Study. Annals of Neurology. 2002;51(5):567-577.

[10] Yancopoulou D, Spillantini MG. Tau protein in familial and sporadic diseases. Neuromolecular Medicine. 2003;4(1-2):3748.

[11] Iqbal K, Alonso Adel C, Chen S, et al. Tau pathology in Alzheimer disease and other tauopathies. Biochimica et Biophysica Acta. 2005;1739(2-3):198-210.

[12] Hutton M, Lendon CL, Rizzu P, et al. Association of missense and $5^{\prime}$-splice-site mutations in tau with the inherited dementia FTDP-17. Nature. 1998;393(6686):702-705.

[13] Poorkaj P, Bird TD, Wijsman E, et al. Tau is a candidate gene for chromosome 17 frontotemporal dementia. Annals of Neurology. 1998;43(6):815-825.

[14] Spillantini MG, Murrell JR, Goedert M, et al. Mutation in the tau gene in familial multiple system tauopathy with presenile dementia. Proceedings of the National Academy of Sciences of the United States of America. 1998;95(13):7737-7741.

[15] Iqbal K, Grundke-Iqbal I, Zaidi T, et al. Defective brain microtubule assembly in Alzheimer's disease. Lancet. 1986;2(8504):421-426.

[16] Alonso Adel C, Zaidi T, Grundke-Iqbal I, et al. Role of abnormally phosphorylated $\tau$ in the breakdown of microtubules in Alzheimer disease. Proceedings of the National Academy of Sciences of the United States of America. 1994;91(12):5562-5566.

[17] Alonso Adel C, Zaidi T, Novak M, et al. Hyperphosphorylation induces self-assembly of tau into tangles of paired helical filaments/straight filaments. Proceedings of the $\mathrm{Na}$ tional Academy of Sciences of the United States of America. 2001;98(12):6923-6928.

[18] Alonso Adel C, Zaidi T, Novak M, et al. Interaction of tau isoforms with Alzheimer's disease abnormally hyperphosphorylated tau and in vitro phosphorylation into the disease-like 
protein. The Journal of Biological Chemistry. 2001;276(41): 37967-37973.

[19] Alonso Adel C, Mederlyova A, Novak M, et al. Promotion of hyperphosphorylation by frontotemporal dementia tau mutations. The Journal of Biological Chemistry. 2004;279(33):34873-34881.

[20] Lucas JJ, Hernandez F, Gomez-Ramos P, et al. Decreased nuclear beta-catenin, tau hyperphosphorylation and neurodegeneration in GSK-3beta conditional transgenic mice. The EMBO Journal. 2001;20(1-2):27-39.

[21] Perez M, Hernandez F, Gomez-Ramos A, et al. Formation of aberrant phosphotau fibrillar polymers in neural cultured cells. European Journal of Biochemistry. 2002;269(5):14841489.

[22] Fath T, Eidenmuller J, Brandt R. Tau-mediated cytotoxicity in a pseudohyperphosphorylation model of Alzheimer's disease. The Journal of Neuroscience. 2002;22(22):9733-9741.

[23] Jackson GR, Wiedau-Pazos M, Sang TK, et al. Human wildtype tau interacts with wingless pathway components and produces neurofibrillary pathology in Drosophila. Neuron. 2002;34(4):509-519.

[24] Stemberger NH, Sternberger LA, Ulrich J. Aberrant neurofilament phosphorylation in Alzheimer disease. Proceedings of the National Academy of Sciences of the United States of America. 1985;82:4274-4276.

[25] Ulloa L, de Garcini EM, Gòmez-Ramos P, et al. Microtubuleassociated protein MAP1B showing a fetal phosphorylation pattern is present in sites of neurofibrillary degeneration in brains of Alzheimer's disease patients. Molecular Brain Research. 1994;26(1-2):113-122.

[26] Vijayan S, El-Akkad E, Grundke-Iqbal I, et al. A pool of $\beta$-tubulin is hyperphosphorylated at serine residues in Alzheimer disease brain. FEBS Letters. 2001;509(3):375-381.

[27] Wang J-Z, Tung YC, Wang Y, et al. Hyperphosphorylation and accumulation of neurofilament proteins in Alzheimer disease brain and in okadaic acid-treated SY5Y cells. FEBS Letters. 2001;507(1):81-87.

[28] Weingarten MD, Lockwood AH, Hwo S-Y, et al. A protein factor essential for microtubule assembly. Proceedings of the National Academy of Sciences of the United States of America. 1975;72(5):1858-1862.

[29] Lee VM, Balin BJ, Otvos L Jr, Trojanowski JQ. A68: a major subunit of paired helical filaments and derivatized forms of normal Tau. Science. 1991;251(4994):675-678.

[30] Neve RL, Harris P, Kosik KS, et al. Identification of cDNA clones for the human microtubule-associated protein tau and chromosomal localization of the genes for tau and microtubule-associated protein 2. Brain Research. 1986;387(3):271-280.

[31] Goedert M, Spillantini MG, Jakes R, et al. Multiple isoforms of human microtubule-associated protein tau: sequences and localization in neurofibrillary tangles of Alzheimer's disease. Neuron. 1989;3(4):519-526.

[32] Lee G, Neve RL, Kosik KS. The microtubule binding domain of tau protein. Neuron. 1989;2(6):1615-1624.

[33] Goode BL, Feinstein SC. Identification of a novel microtubule binding and assembly domain in the developmentally regulated inter-repeat region of tau. The Journal of Cell Biology. 1994;124(5):769-782.

[34] Panda D, Goode BL, Feinstein SC, et al. Kinetic stabilization of microtubule dynamics at steady state by tau and microtubule-binding domains of tau. Biochemistry. 1995; 34(35):11117-11127.
[35] Hirokawa N, Shiomura Y, Okabe S. Tau proteins: the molecular structure and mode of binding on microtubules. The Journal of Cell Biology. 1988;107(4):1449-1459.

[36] Brandt R, Leger J, Lee G. Interaction of tau with the neural plasma membrane mediated by tau's amino-terminal projection domain. The Journal of Cell Biology. 1995;131(5):13271340 .

[37] Utton MA, Gibb GM, Burdett ID, et al. Functional differences of tau isoforms containing 3 or 4 C-terminal repeat regions and the influence of oxidative stress. The Journal of Biological Chemistry. 2001;276(36):34288-34297.

[38] Stanford PM, Shepherd CE, Halliday GM, et al. Mutations in the tau gene that cause an increase in three repeat tau and frontotemporal dementia. Brain. 2003;126(pt 4):814-826.

[39] Kosik KS, Orecchio LD, Bakalis S, et al. Developmentally regulated expression of specific tau sequences. Neuron. 1989;2(4):1389-1397.

[40] Goedert M, Jakes R. Expression of separate isoforms of human tau protein: correlation with the tau pattern in brain and effects on tubulin polymerization. The EMBO Journal. 1990;9(13):4225-4230.

[41] Tatebayashi Y, Haque N, Tung YC, et al. Role of tau phosphorylation by glycogen synthase kinase- $3 \beta$ in the regulation of organelle transport. Journal of Cell Science. 2004;117(pt 9):1653-1663.

[42] Ebneth A, Godemann R, Stamer K, et al. Overexpression of tau protein inhibits kinesin-dependent trafficking of vesicles, mitochondria, and endoplasmic reticulum: implications for Alzheimer's disease. The Journal of Cell Biology. 1998;143(3):777-794.

[43] Ishihara T, Hong M, Zhang B, et al. Age-dependent emergence and progression of a tauopathy in transgenic mice overexpressing the shortest human tau isoform. Neuron. 1999;24(3):751-762.

[44] Spittaels K, Van den Haute C, Van Dorpe J, et al. Prominent axonopathy in the brain and spinal cord of transgenic mice overexpressing four-repeat human tau protein. The American Journal of Pathology. 1999;155(6):2153-2165.

[45] Lewis J, McGowan E, Rockwood J, et al. Neurofibrillary tangles, amyotrophy and progressive motor disturbance in mice expressing mutant (P301L) tau protein. Nature Genetics. 2000;25(4):402-405.

[46] Probst A, Gotz J, Wiederhold KH, et al. Axonopathy and amyotrophy in mice transgenic for human four-repeat tau protein. Acta Neuropathologica (Berl). 2000;99(5):469-481.

[47] Rendon A, Jung D, Jancsik V. Interaction of microtubules and microtubule-associated proteins (MAPs) with rat brain mitochondria. The Biochemical Journal. 1990;269(2):555-556.

[48] Kampers T, Friedhoff P, Biernat J, et al. RNA stimulates aggregation of microtubule-associated protein tau into Alzheimerlike paired helical filaments. FEBS Letters. 1996;399(3):344349.

[49] Hua Q, He RQ, Haque N, et al. Microtubule associated protein tau binds to double-stranded but not single-stranded DNA. Cellular and Molecular Life Sciences. 2003;60(2):413421.

[50] Lee G, Newman ST, Gard DL, Band H, Panchamoorthy G. Tau interacts with src-family non-receptor tyrosine kinases. Journal of Cell Science. 1998;111(pt 21):3167-3177.

[51] Bhaskar K, Yen S-H, Lee G. Disease-related modifications in tau affect the interaction between Fyn and Tau. The Journal of Biological Chemistry. 2005;280(42):35119-35125. 
[52] Jaspert A, Fahsold R, Grehl H, et al. Myotonic dystrophy: correlation of clinical symptoms with the size of the CTG trinucleotide repeat. Journal of Neurology. 1995;242(2):99-104.

[53] Jenkins SM, Johnson GV. Tau complexes with phospholipase C-gamma in situ. NeuroReport. 1998;9(1):67-71.

[54] Cleveland DW, Hwo SY, Kirschner MW. Physical and chemical properties of purified tau factor and the role of tau in microtubule assembly. Journal of Molecular Biology. 1977; 116(2):227-247.

[55] Lindwall G, Cole RD. Phosphorylation affects the ability of tau protein to promote microtubule assembly. The Journal of Biological Chemistry. 1984;259(8):5301-5305.

[56] Ksiezak-Reding H, Liu WK, Yen SH, et al. Phosphate analysis and dephosphorylation of modified tau associated with paired helical filaments. Brain Research. 1992;597(2):209219.

[57] Köpke E, Tung Y-C, Shaikh S, et al. Microtubule-associated protein tau. Abnormal phosphorylation of a non-paired helical filament pool in Alzheimer disease. The Journal of Biological Chemistry. 1993;268(32):24374-24384.

[58] Kenessey A, Yen SH. The extent of phosphorylation of fetal tau is comparable to that of PHF-tau from Alzheimer paired helical filaments. Brain Research. 1993;629(1):40-46.

[59] Matsuo ES, Shin RW, Billingsley ML, et al. Biopsy-derived adult human brain tau is phosphorylated at many of the same sites as Alzheimer's disease paired helical filament tau. Neuron. 1994;13(4):989-1002.

[60] Garver TD, Harris KA, Lehman RA, et al. Tau phosphorylation in human, primate, and rat brain: evidence that a pool of tau is highly phosphorylated in vivo and is rapidly dephosphorylated in vitro. Journal of Neurochemistry. 1994; 63(6):2279-2287.

[61] Iqbal K, Zaidi T, Bancher C, et al. Alzheimer paired helical filaments. Restoration of the biological activity by dephosphorylation. FEBS Letters. 1994;349(1):104-108.

[62] Drechsel DN, Hyman AA, Cobb MH, Kirschner MW. Modulation of the dynamic instability of tubulin assembly by the microtubule-associated protein tau. Molecular Biology of the Cell. 1992;3(10):1141-1154.

[63] Bramblett GT, Goedert M, Jakes R, et al. Abnormal tau phosphorylation at Ser396 in Alzheimer's disease recapitulates development and contributes to reduced microtubule binding. Neuron. 1993;10(6):1089-1099.

[64] Yoshida H, Ihara Y. Tau in paired helical filaments is functionally distinct from fetal tau: assembly incompetence of paired helical filament-tau. Journal of Neurochemistry. 1993;61(3):1183-1186.

[65] Biernat J, Gustke N, Drewes G, et al. Phosphorylation of $\mathrm{Ser}^{262}$ strongly reduces binding of tau to microtubules: distinction between PHF-like immunoreactivity and microtubule binding. Neuron. 1993;11(1):153-163.

[66] Alonso Adel C, Grundke-Iqbal I, Iqbal K. Alzheimer's disease hyperphosphorylated tau sequesters normal tau into tangles of filaments and disassembles microtubules. Nature Medicine. 1996;2(7):783-787.

[67] Wang J-Z, Gong C-X, Zaidi T, et al. Dephosphorylation of Alzheimer paired helical filaments by protein phosphatase2A and -2B. The Journal of Biological Chemistry. 1995; 270(9):4854-4860.

[68] Wang J-Z, Grundke-Iqbal I, Iqbal K. Glycosylation of microtubule-associated protein tau: an abnormal posttranslational modification in Alzheimer's disease. Nature Medicine. 1996;2(8):871-875.
[69] Gong C-X, Lidsky T, Wegiel J, et al. Phosphorylation of microtubule-associated protein tau is regulated by protein phosphatase $2 \mathrm{~A}$ in mammalian brain. Implications for neurofibrillary degeneration in Alzheimer's disease. The Journal of Biological Chemistry. 2000;275(8):5535-5544.

[70] Khatoon S, Grundke-Iqbal I, Iqbal K. Brain levels of microtubule-associated protein tau are elevated in Alzheimer's disease: a radioimmuno-slot-blot assay for nanograms of the protein. Journal of Neurochemistry. 1992;59(2):750753.

[71] Khatoon S, Grundke-Iqbal I, Iqbal K. Levels of normal and abnormally phosphorylated tau in different cellular and regional compartments of Alzheimer disease and control brains. FEBS Letters. 1994;351(1):80-84.

[72] Kohnken R, Buerger K, Zinkowski R, et al. Detection of tau phosphorylated at threonine 231 in cerebrospinal fluid of Alzheimer's disease patients. Neuroscience Letters. 2000;287(3):187-190.

[73] Ishiguro K, Ohno H, Arai H, et al. Phosphorylated tau in human cerebrospinal fluid is a diagnostic marker for Alzheimer's disease. Neuroscience Letters. 1999;270(2):91-94.

[74] Hampel H, Buerger K, Kohnken R, et al. Tracking of Alzheimer's disease progression with cerebrospinal fluid tau protein phosphorylated at threonine 231. Annals of Neurology. 2001;49(4):545-546.

[75] Hampel H, Buerger K, Zinkowski R, et al. Measurement of phosphorylated tau epitopes in the differential diagnosis of Alzheimer disease: a comparative cerebrospinal fluid study. Archives of General Psychiatry. 2004;61(1):95-102.

[76] Parnetti L, Lanari A, Amici S, et al. CSF phosphorylated tau is a possible marker for discriminating Alzheimer's disease from dementia with Lewy bodies. Neurological Sciences. 2001;22(1):77-78.

[77] Vanmechelen E, Van Kerschaver E, Blennow K, et al. CSFphospho-tau (181P) as a promising marker for discriminating Alzheimer's disease from dementia with Lewy bodies. In: Iqbal K, Sissodia S, Winblad B, eds. Alzheimer's Disease: Advances in Etiology, Pathogenesis and Therapeutics. Chichester, UK: John Wiley \& Sons; 2001:285-291.

[78] Itoh N, Arai H, Urakami K, et al. Large-scale, multicenter study of cerebrospinal fluid tau protein phosphorylated at serine 199 for the antemortem diagnosis of Alzheimer's disease. Annals of Neurology. 2001;50(2):150-156.

[79] $\mathrm{Hu} Y Y, \mathrm{He} S S$, Wang XC, et al. Levels of nonphosphorylated and phosphorylated tau in cerebrospinal fluid of Alzheimer's disease patients : an ultrasensitive bienzymesubstrate-recycle enzyme-linked immunosorbent assay. The American Journal of Pathology. 2002;160(4):1269-1278.

[80] Buerger K, Zinkowski R, Teipel SJ, et al. Differential diagnosis of Alzheimer disease with cerebrospinal fluid levels of tau protein phosphorylated at threonine 231. Archives of Neurology. 2002;59(8):1267-1272.

[81] Goedert M, Spillantini MG, Cairns NJ, et al. Tau proteins of Alzheimer paired helical filaments: abnormal phosphorylation of all six brain isoforms. Neuron. 1992;8(1):159-168.

[82] Gong C-X, Liu F, Grundke-Iqbal I, et al. Post-translational modifications of tau protein in Alzheimer's disease. Journal of Neural Transmission. 2005;112(6):813-838.

[83] Gong C-X, Singh TJ, Grundke-Iqbal I, et al. Phosphoprotein phosphatase activities in Alzheimer disease brain. Journal of Neurochemistry. 1993;61(3):921-927.

[84] Gong C-X, Shaikh S, Wang J-Z, Zaidi T, et al. Phosphatase activity toward abnormally phosphorylated $\tau$ : decrease in 
Alzheimer disease brain. Journal of Neurochemistry. 1995; 65(2):732-738.

[85] Vogelsberg-Ragaglia V, Schuck T, Trojanowski JQ, et al. PP2A mRNA expression is quantitatively decreased in Alzheimer's disease hippocampus. Experimental Neurology. 2001;168(2):402-412.

[86] Loring JF, Wen X, Lee JM, et al. A gene expression profile of Alzheimer's disease. DNA and Cell Biology. 2001;20(11):683695.

[87] Sontag E, Luangpirom A, Hladik C, et al. Altered expression levels of the protein phosphatase $2 \mathrm{~A} \mathrm{AB} \alpha \mathrm{C}$ enzyme are associated with Alzheimer disease pathology. Journal of Neuropathology and Experimental Neurology. 2004;63(4):287301.

[88] Liu F, Grundke-Iqbal I, Iqbal K, et al. Contributions of protein phosphatases PP1, PP2A, PP2B and PP5 to the regulation of tau phosphorylation. The European Journal of Neuroscience. 2005;22(8):1942-1950.

[89] Liu F, Iqbal K, Grundke-Iqbal I, et al. Dephosphorylation of tau by protein phosphatase 5: impairment in Alzheimer's disease. The Journal of Biological Chemistry. 2005;280(3):17901796.

[90] Hoffmann R, Lee VM, Leight S, et al. Unique Alzheimer's disease paired helical filament specific epitopes involve double phosphorylation at specific sites. Biochemistry. 1997; 36(26):8114-8124.

[91] Hasegawa M, Jakes R, Crowther R, et al. Characterization of mAb AP422, a novel phosphorylation-dependent monoclonal antibody against tau protein. FEBS Letters. 1996;384(1): 25-30.

[92] Bussiere T, Hof PR, Mailliot C, et al. Phosphorylated serine 422 on tau proteins is a pathological epitope found in several diseases with neurofibrillary degeneration. Acta Neuropathologica (Berl). 1999;97(3):221-230.

[93] Lee G, Thangavel R, Sharma VM, et al. Phosphorylation of tau by fyn: implications for Alzheimer's disease. The Journal of Neuroscience. 2004;24(9):2304-2312.

[94] Williamson R, Scales T, Clark BR, et al. Rapid tyrosine phosphorylation of neuronal proteins including tau and focal adhesion kinase in response to amyloid- $\beta$ peptide exposure: involvement of Src family protein kinases. The Journal of Neuroscience. 2002;22(1):10-20.

[95] Derkinderen P, Scales TM, Hanger DP, et al. Tyrosine 394 is phosphorylated in Alzheimer's paired helical filament tau and in fetal tau with c-Abl as the candidate tyrosine kinase. The Journal of Neuroscience. 2005;25(28):6584-6593.

[96] Rapoport M, Dawson HN, Binder LI, et al. Tau is essential to beta -amyloid-induced neurotoxicity. Proceedings of the $\mathrm{Na}$ tional Academy of Sciences of the United States of America. 2002;99(9):6364-6369.

[97] Brich J, Shie FS, Howell BW, et al. Genetic modulation of tau phosphorylation in the mouse. The Journal of Neuroscience. 2003;23(1):187-192.

[98] Lee VMY, Goedert M, Trojanowski JQ. Neurodegenerative tauopathies. Annual Review of Neuroscience. 2001;24:11211159.

[99] Bancher C, Brunner C, Lassman H, et al. Accumulation of abnormally phosphorylated tau precedes the formation of neurofibrillary tangles in Alzheimer's disease. Brain Research. 1989;477(1-2):90-99.

[100] Bancher C, Grundke-Iqbal I, Iqbal K, et al. Abnormal phosphorylation of tau precedes ubiquitination in neurofibrillary pathology of Alzheimer disease. Brain Research. 1991;539(1):11-18.
[101] Braak E, Braak H, Mandelkow E-M. A sequence of cytoskeletal changes related to the formation of neurofibrillary tangles and neuropil threads. Acta Neuropathologica. 1994;87:544567.

[102] Sengupta A, Kabat J, Novak M, et al. Maximal inhibition of tau binding to microtubules requires the phosphorylation of tau at both Thr 231 and Ser 262. Neurobiology of Aging. 1998;19S:S124-S524.

[103] Schneider A, Biernat J, von Bergen M, et al. Phosphorylation that detaches tau protein from microtubules (Ser262, Ser214) also protects it against aggregation into Alzheimer paired helical filaments. Biochemistry. 1999;38(12):3549-3558.

[104] Abraha A, Ghoshal N, Gamblin TC, et al. C-terminal inhibition of tau assembly in vitro and in Alzheimer's disease. Journal of Cell Science. 2000;113(pt 21):3737-3745.

[105] Haase C, Stieler J, Arendt T, et al. Pseudophosphorylation of tau protein alters its ability for self-aggregation. Journal of Neurochemistry. 2004;88(6):1509-1520.

[106] Ferrari A, Hoerndli F, Baechi T, et al. Beta-amyloid induces paired helical filament-like tau filaments in tissue culture. The Journal of Biological Chemistry. 2003;278(41):4016240168.

[107] Harada A, Oguchi K, Okabe S, et al. Altered microtubule organization in small-calibre axons of mice lacking tau protein. Nature. 1994;369(6480):488-491.

[108] Alonso Adel C, Grundke-Iqbal I, Barra HS, et al. Abnormal phosphorylation of tau and the mechanism of Alzheimer neurofibrillary degeneration: sequestration of microtubuleassociated proteins 1 and 2 and the disassembly of microtubules by the abnormal tau. Proceedings of the $\mathrm{Na}$ tional Academy of Sciences of the United States of America. 1997;94(1):298-303.

[109] Hernandez F, Borrell J, Guaza C, et al. Spatial learning deficit in transgenic mice that conditionally over-express GSK-3beta in the brain but do not form tau filaments. Journal of Neurochemistry. 2002;83(6):1529-1533.

[110] Lee VMY, Kenyon TK, Trojanowski JQ. Transgenic animal models of tauopathies. Biochimica et Biophysica Acta. 2005;1739(2-3):251-259.

[111] Kayed R, Head E, Thompson JL, et al. Common structure of soluble amyloid oligomers implies common mechanism of pathogenesis. Science. 2003;300(5618):486-489.

[112] Sanbe A, Osinska H, Villa C, et al. Reversal of amyloidinduced heart disease in desmin-related cardiomyopathy. Proceedings of the National Academy of Sciences of the United States of America. 2005;102(38):13592-13597.

[113] Lau LF, Schachter JB, Seymour PA, et al. Tau protein phosphorylation as a therapeutic target in Alzheimer's disease. Current Topics in Medicinal Chemistry. 2002;2(4):395-415.

[114] Tian Q, Wang J. Role of serine/threonine protein phosphatase in Alzheimer's disease. Neurosignals. 2002;11(5):262-269.

[115] Johnson GV, Stoothoff WH. Tau phosphorylation in neuronal cell function and dysfunction. Journal of Cell Science. 2004;117(pt 24):5721-5729.

[116] Goedert M, Jakes R, Qi Z, et al. Protein phosphatase 2A is the major enzyme in brain that dephosphorylates tau protein phosphorylated by proline-directed protein kinases or cyclic AMP-dependent protein kinase. Journal of Neurochemistry. 1995;65(6):2804-2807.

[117] Sontag E, Nunbhakdi-Craig V, Lee G, et al. Regulation of the phosphorylation state and microtubule-binding activity of Tau by protein phosphatase 2A. Neuron. 1996;17(6):12011207. 
[118] Sontag E, Nunbhakdi-Craig V, Lee G, et al. Molecular interactions among protein phosphatase $2 \mathrm{~A}$, tau, and microtubules. Implications for the regulation of tau phosphorylation and the development of tauopathies. The Journal of Biological Chemistry. 1999;274(36):25490-25498.

[119] Bennecib M, Gong C-X, Grundke-Iqbal I, et al. Role of protein phosphatase-2A and -1 in the regulation of GSK-3, cdk5 and $\mathrm{cdc} 2$ and the phosphorylation of tau in rat forebrain. FEBS Letters. 2000;485(1):87-93.

[120] Kins S, Crameri A, Evans DR, et al. Reduced protein phosphatase $2 \mathrm{~A}$ activity induces hyperphosphorylation and altered compartmentalization of tau in transgenic mice. The Journal of Biological Chemistry. 2001;276(41):38193-38200.

[121] Liu F, Grundke-Iqbal I, Iqbal K, et al. Truncation and activation of calcineurin A by calpain 1 in Alzheimer disease brain. The Journal of Biological Chemistry. 2005;280(45):3775537762.

[122] Sengupta A, Wu Q, Grundke-Iqbal I, et al. Potentiation of GSK-3-catalyzed Alzheimer-like phosphorylation of human tau by cdk5. Molecular and Cellular Biochemistry. 1997;167(12):99-105.

[123] Wang J-Z, Wu Q, Smith A, et al. $\tau$ is phosphorylated by GSK3 at several sites found in Alzheimer disease and its biological activity markedly inhibited only after it is prephosphorylated by A-kinase. FEBS Letters. 1998;436(1):28-34.

[124] Liu SJ, Zhang JY, Li HL, et al. Tau becomes a more favorable substrate for GSK-3 when it is prephosphorylated by PKA in rat brain. The Journal of Biological Chemistry. 2004;279(48):50078-50088.

[125] Cho JH, Johnson GV. Glycogen synthase kinase 3beta phosphorylates tau at both primed and unprimed sites. Differential impact on microtubule binding. The Journal of Biological Chemistry. 2003;278(1):187-193.

[126] Cho JH, Johnson GV. Primed phosphorylation of tau at Thr231 by glycogen synthase kinase 3beta (GSK3beta) plays a critical role in regulating tau's ability to bind and stabilize microtubules. Journal of Neurochemistry. 2004;88(2):349-358.

[127] Sun L, Wang X, Liu S, et al. Bilateral injection of isoproterenol into hippocampus induces Alzheimer-like hyperphosphorylation of tau and spatial memory deficit in rat. FEBS Letters. 2005;579(1):251-258.

[128] Liu SJ, Zhang AH, Li HL, et al. Overactivation of glycogen synthase kinase-3 by inhibition of phosphoinositol-3 kinase and protein kinase $\mathrm{C}$ leads to hyperphosphorylation of tau and impairment of spatial memory. Journal of Neurochemistry. 2003;87(6):1333-1344.

[129] Baki L, Shioi J, Wen P, et al. PS1 activates PI3K thus inhibiting GSK-3 activity and tau overphosphorylation: effects of FAD mutations. The EMBO Journal. 2004;23(13):2586-2596.

[130] Li X, Lu F, Tian Q, et al. Activation of glycogen synthase kinase-3 induces Alzheimer-like tau hyperphosphorylation in rat hippocampus slices in culture. Journal of Neural Transmission. 2006;113(1):93-102.

[131] Deng YQ, Xu GG, Duan P, et al. Effects of melatonin on wortmannin-induced tau hyperphosphorylation. Acta Pharmacologica Sinica. 2005;26(5):519-526.

[132] Patrick GN, Zukerberg L, Nikolic M, et al. Conversion of p35 to p25 deregulates Cdk5 activity and promotes neurodegeneration. Nature. 1999;402(6762):615-622.

[133] Yoo BC, Lubec G. p25 protein in neurodegeneration. Nature. 2001;411(6839):763-764.

[134] Taniguchi S, Fujita Y, Hayashi S, et al. Calpain-mediated degradation of p35 to p25 in postmortem human and rat brains. FEBS Letters. 2001;489(1):46-50.
[135] Nguyen KC, Rosales JL, Barboza M, et al. Controversies over p25 in Alzheimer's disease. Journal of Alzheimer's Disease. 2002;4(2):123-126.

[136] Tandon A, Yu H, Wang L, et al. Brain levels of CDK5 activator p25 are not increased in Alzheimer's or other neurodegenerative diseases with neurofibrillary tangles. Journal of Neurochemistry. 2003;86(3):572-581.

[137] Tanaka T, Zhong J, Iqbal K, et al. The regulation of phosphorylation of tau in SY5Y neuroblastoma cells: the role of protein phosphatases. FEBS Letters. 1998;426(2):248-254.

[138] Bennecib M, Gong C-X, Grundke-Iqbal I, et al. Inhibition of PP-2A upregulates CaMKII in rat forebrain and induces hyperphosphorylation of tau at Ser 262/356. FEBS Letters. 2001;490(1-2):15-22.

[139] Pei J-J, Gong C-X, An W, et al. Okadaic-acid-induced inhibition of protein phosphatase $2 \mathrm{~A}$ produces activation of mitogen-activated protein kinases ERK1/2, MEK1/2, and p70 S6, similar to that in Alzheimer's disease. The American Journal of Pathology. 2003;163(3):845-858.

[140] Kins S, Kurosinski P, Nitsch RM, Gotz J. Activation of the ERK and JNK signaling pathways caused by neuron-specific inhibition of PP2A in transgenic mice. The American Journal of Pathology. 2003;163(3):833-843.

[141] An W-L, Cowburn RF, Li L, et al. Up-regulation of phosphorylated/activated p70 S6 kinase and its relationship to neurofibrillary pathology in Alzheimer's disease. The American Journal of Pathology. 2003;163(2):591-607.

[142] Tanimukai H, Grundke-Iqbal I, Iqbal K. Up-regulation of inhibitors of protein phosphatase-2A in Alzheimer's disease. The American Journal of Pathology. 2005;166(6):1761-1771.

[143] Arnold CS, Johnson GV, Cole RN, et al. The microtubuleassociated protein tau is extensively modified with O-linked $\mathrm{N}$-acetylglucosamine. The Journal of Biological Chemistry. 1996;271(46):28741-28744.

[144] Lefebvre T, Ferreira S, Dupont-Wallois L, et al. Evidence of a balance between phosphorylation and O-GlcNAc glycosylation of Tau proteins - a role in nuclear localization. Biochimica et Biophysica Acta. 2003;1619(2):167-176.

[145] Liu F, Iqbal K, Grundke-Iqbal I, et al. O-GlcNAcylation regulates phosphorylation of tau: a mechanism involved in Alzheimer's disease. Proceedings of the National Academy of Sciences of the United States of America. 2004;101(29):1080410809.

[146] Comer FI, Hart GW. O-Glycosylation of nuclear and cytosolic proteins. Dynamic interplay between O-GlcNAc and Ophosphate. The Journal of Biological Chemistry. 2002;275(38): 29179-29182.

[147] Robertson LA, Moya KL, Breen KC. The potential role of tau protein O-glycosylation in Alzheimer's disease. Journal of Alzheimer's Disease. 2004;6(5):489-495.

[148] Gong C-X, Liu F, Grundke-Iqbal I, et al. Impaired brain glucose metabolism leads to Alzheimer neurofibrillary degeneration through a decrease in tau O-GlcNAcylation. Journal of Alzheimer's Disease. 2006; in press.

[149] Takahishi M, Tsumioka Y, Yamada T, et al. Glycosylation of microtubule-associated protein tau in Alzheimer's disease brain. Acta Neuropathologica (Berl). 1999;97(6):635-641.

[150] Liu F, Zaidi T, Grundke-Iqbal I, et al. Role of glycosylation in hyperphosphorylation of tau in Alzheimer's disease. FEBS Letters. 2002;512(1-3):101-106.

[151] Liu F, Zaidi T, Grandke-Iqbal I, et al. Aberrant glycosylation modulates phosphorylation of tau by protein kinase A and dephosphorylation of tau by protein phosphatase $2 \mathrm{~A}$ and 5 . Neuroscience. 2002;115(3):829-837. 
[152] Liu F, Grundke-Iqbal I, Iqbal K, et al. Involvement of aberrant glycosylation in phosphorylation of tau by $\mathrm{cdk} 5$ and GSK-3 $\beta$. FEBS Letters. 2002;530(1-3):209-214.

[153] Winblad B, Poritis N. Memantine in severe dementia: results of the 9M-Best Study (Benefit and efficacy in severely demented patients during treatment with memantine). International Journal of Geriatric Psychiatry. 1999;14(2):135-146.

[154] Reisberg B, Doody A, Stoffler A. Memantine in moderateto-severe Alzheimer's disease. The New England Journal of Medicine. 2003;348(14):1333-1341.

[155] Li L, Sengupta A, Haque N, et al. Memantine inhibits and reverses the Alzheimer type abnormal hyperphosphorylation of tau and associated neurodegeneration. FEBS Letters. 2004;566(1-3):261-269.

[156] Li SP, Deng YQ, Wang YP, et al. Melatonin protects SHSY5Y neuroblastoma cells from calyculin A-induced neurofilament impairment and neurotoxicity. Journal of Pineal Research. 2004;36(3):186-191.

[157] Li XC, Wang ZF, Zhang JX, et al. Effect of melatonin on calyculin A-induced tau hyperphosphorylation. European Journal of Pharmacology. 2005;510(1-2):25-30.

[158] Zhu LQ, Wang SH, Ling ZQ, et al. Effect of inhibiting melatonin biosynthesis on spatial memory retention and tau phosphorylation in rat. Journal of Pineal Research. 2004;37(2):71-77.

[159] Wang DL, Ling ZQ, Cao FY, et al. Melatonin attenuates isoproterenol-induced protein kinase A overactivation and tau hyperphosphorylation in rat brain. Journal of Pineal Research. 2004;37(1):11-16. 


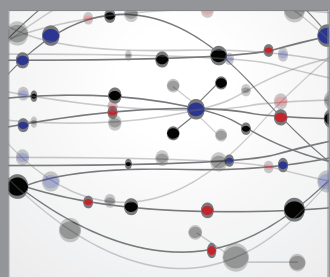

The Scientific World Journal
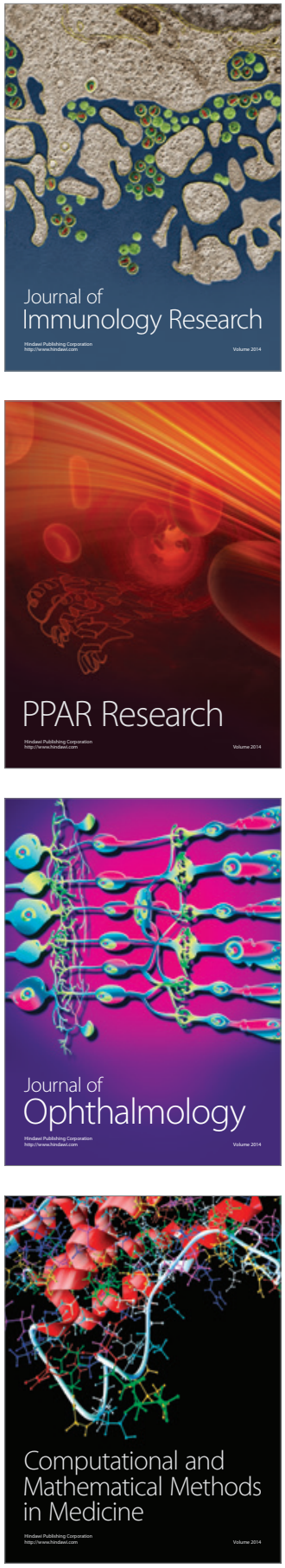

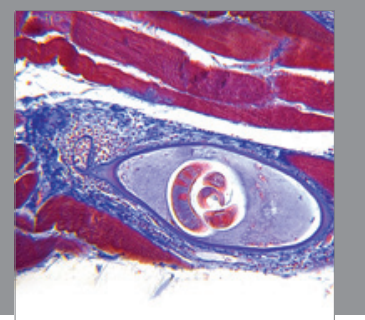

Gastroenterology

Research and Practice
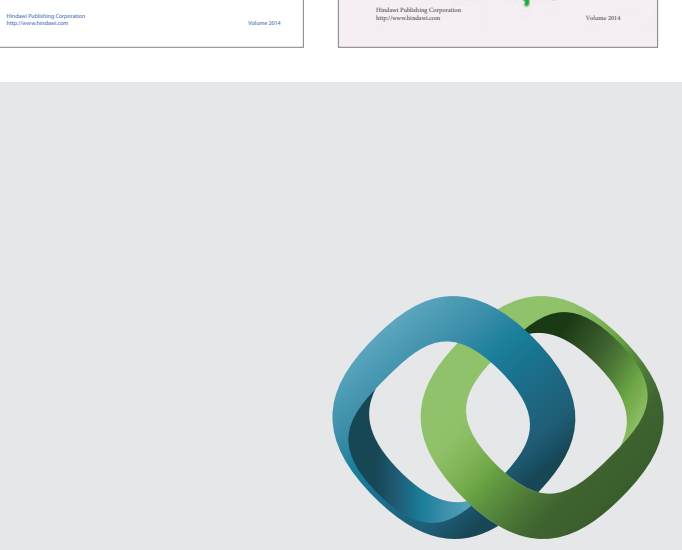

\section{Hindawi}

Submit your manuscripts at

http://www.hindawi.com
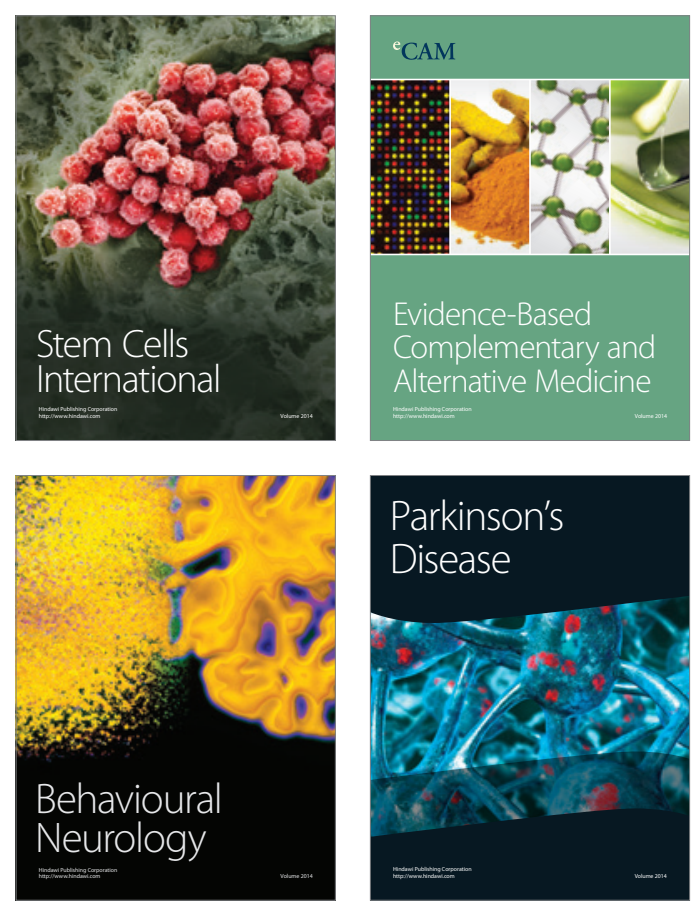

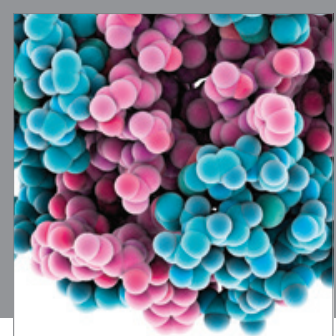

Journal of
Diabetes Research

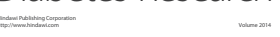

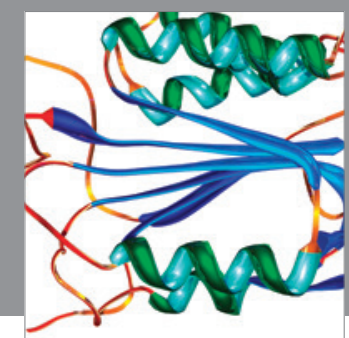

Disease Markers
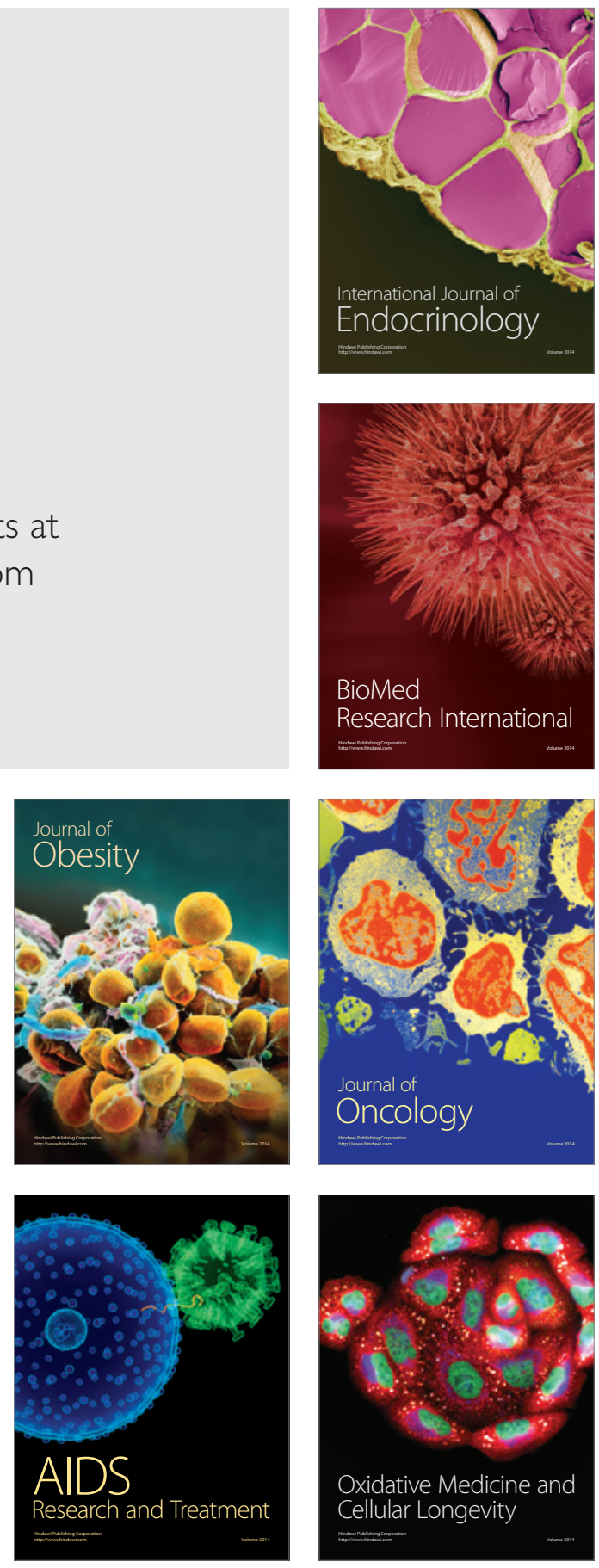